\title{
Rounding Phenomenon in the OTC Market
}

\author{
Daoping He \\ San Jose State University \\ Yao Tian \\ San Jose State University \\ Caixing Liu \\ California State University
}

This study investigates the rounding phenomenon in the over-the-counter (OTC) market and finds that (1) similar to firms listed in the major U.S. stock markets, OTC-listed firms manipulate their reported earnings and revenues through rounding; (2) rounding manipulation is more severe in the OTC market than in the major stock markets and (3) the enforcement of SEC's mandatory disclosure requirements in 1999 reduced OTC firms' rounding manipulation activities. This study extends the rounding manipulation literature and provides the first piece of empirical evidence of rounding manipulation in the OTC market. It helps scholars and investors better understand firms in the OTC market. This study also provides feedback to policy makers and regulators on the effectiveness of the SEC mandatory disclosure requirement on OTC firms' financial reporting quality.

Keywords: earnings management, rounding phenomenon

\section{INTRODUCTION}

The U.S. OTC market is composed of the OTC Pink Sheets (OTCPS) and OTC Bulletin Board (OTCBB) markets. The OTC market represents an economically significant portion of public listed firms in the United States (Jiang, et al., 2016). In 2005, the total OTC market capitalization was more than twice the size of the American Stock Exchange (AMEX), and the total number of listed OTC companies was twice the number of companies in the NASDAQ market (SEC 2006). However, there has been very limited research on the OTC market. For instance, the rounding manipulation phenomenon has been extensively documented for firms listed in major stock markets, but it has not been examined in the OTC market. This study investigates the rounding phenomenon in the OTC market. In particular, it examines (1) whether OTC-listed firms manipulate their reported earnings and revenues by rounding up these numbers, (2) whether the rounding phenomenon in the OTC market is more severe than that in the U.S. major stock markets, and (3) whether mandatory disclosure requirements constrain OTC firms' rounding manipulation activities.

Prior literature postulates that managers tend to round up reported earnings and revenues to achieve key reference points represented by N x 10K (Carlsaw, 1988; Thomas, 1989; He et al., 2013). Empirically, 
this phenomenon is demonstrated by an excess of zeros and a lack of nines in the second digit of reported earnings and revenues for firms listed in major U.S. stock markets (New York Stock Exchange, NASDAQ, and American Stock Exchange). Researchers cite this phenomenon as evidence that managers engage in earnings management activities to provide a rosy picture of the firms' performance.

The study examines the rounding phenomenon in the OTC market. Since firms reporting positive earnings (referred to as profit firms thereof) have incentives to report higher earnings, while firms reporting negative earnings (referred to as loss firms thereof) have incentives to report a smaller loss, this study examines the rounding behavior by profit firms and loss firms separately. It finds that profit firms report significantly higher percentage of zeros in the second digit of earnings, while loss firms report significantly higher percentage of nines in the second digit of earnings. These results suggest that OTC profit firms round earnings up to report a higher earnings, while OTC loss firms round down negative earnings to report a smaller loss. This study also examine firms' rounding behavior in the two OTC markets (OTCBB and OTCPS) separately to gain further insights into the OTC market. In comparing the rounding phenomenon in the two OTC markets, we find that firms listed in OTCBB market are more aggressive in rounding up reported earnings and less aggressive in rounding up reported revenues, as compared to firms listed in the OTCPS market.

To gain more insights into the extent of rounding manipulation in the OTC market, this study compares the rounding behavior of OTC-listed firms and firms listed in the major U.S. exchange markets. Results show that OTC-listed firms are more aggressive in rounding their reported earnings and revenues than firms listed in major US stock markets.

Mandatory disclosure regulations may constrain firms' rounding behavior. In early 1999, SEC approved the eligibility rule under which all OTCBB-listed firms must comply with the reporting regulations of the 1934 Securities Exchange Act; however, this rule does not apply to firms listed in OTCPS market. In this study, we investigate whether the enhanced disclosure requirements constrain OTCBB firms' rounding behavior. We find that in the years prior to the enforcement of the eligibility rule (prior to 1999), OTCBB firms engage in rounding manipulation of both earnings and revenues, while after the enforcement of the eligibility rule (after 1999), OTCBB firms' rounding of earnings and revenues are no longer statistically significant. To further investigate whether the decrease in rounding manipulation could be due to time period effect (rather than the effect of the enforcement of the eligibility rule), we also examine the rounding behavior by OTCPS firms after the enforcement of the eligibility rule in 1999. We find that, unlike the OTCBB firms, OTCPS firms still engage in rounding manipulation of earnings and revenue after 1999. Since the enforcement of the eligibility rule in 1999 applies only to OTCBB firms and not OTCPS firms, these results provide evidence that the enforcement of the eligibility rule reduced firms' rounding behavior in the OTCBB market.

This paper contributes to the current literature as follows. First, although there have been extensive research on the rounding phenomenon in the major U.S. stock markets, it is unknown whether the rounding phenomenon extends to the OTC market. This study contributes to the rounding phenomenon literature by providing the first piece of empirical evidence of the rounding phenomenon in the OTC market. Second, regardless of the large size of OTC market, there has been very limited research about the OTC market. Results from this study help scholars and investors better understand the OTC market. Lastly, by documenting the change in rounding behavior of firms in the OTCBB market prior to and after the enforcement of the eligibility rule in 1999, this study provides feedback to policy makers and regulators on the effectiveness of the mandatory SEC disclosure requirement on OTC firms' financial reporting quality.

The rest of the paper is organized as follows. Section 2 reviews related literature and develops hypotheses. Section 3 provides sample statistics and describes the research methodology. Section 4 presents empirical results, and section 5 concludes.

\section{LITERATURE REVIEW AND HYPOTHESIS DEVELOPMENT}

The rounding phenomenon in reported earnings has been extensively examined across industries and around the world after the pioneering studies of Carslaw (1988) and Thomas (1989). Carslaw (1988) 
examines the rounding phenomenon among New Zealand firms and documents the significant departure of reported earnings numbers from expectations. He finds a much higher-than-expected frequency of zeros and less-than-expected nines as the second digit in reported earnings. Thomas (1989) examines U.S. firms' reported earnings and finds similar patterns. Das and Zhang (2003) extend Thomas (1989) and document that managers exercise their discretion to round up earnings and firms use working capital accruals to round up earnings to meet behavioral thresholds, such as reporting positive earnings, sustaining recent levels of performance and meeting analysts' forecasts. Guan et al. (2008) analyze the pattern of rounding of reported earnings across U.S. industries and find that high-tech firms tend to have the highest occurrences of rounding. In a recent study, He et al. (2012) examine the rounding phenomenon in reported revenues and find that rounding manipulation is also prevalent in reported revenues. The rounding manipulation is more severe in reported earnings for profit firms than that in reported revenues. However, for loss firms, it is more severe in reported revenues than in reported earnings. Several studies focus on rounding behaviors in reported earnings from the international perspective. Kinnunen and Koskela (2003) document, in a sample of almost 22,000 firms in 18 countries, the tendency to exercise cosmetic earnings management worldwide. Skousen et al (2004) find that Japanese managers tend to manipulate earnings by rounding up the earnings numbers to achieve key reference points.

There are two competing explanations for the rounding phenomenon. The valuation perspective is supported by findings that since human beings have an only limited amount of memory, they tend to store only the most relevant bits of information about a price (Brenner \& Brenner, 1982). In the same way that consumers perceive a product priced at $\$ 2.00$ to be much higher than the one priced at $\$ 1.99$, investors perceive reported earnings or revenues of $\$ 2,000$ to be much higher than that of $\$ 1,990$. Thus, managers may have incentives to round up earnings and revenues in order to raise investors' perception of a firm's performance. On the other hand, the contracting perspective argues that because of uncertainty related to managers' productive efforts, lending and bonus contracts tend to be based on ex ante estimates and are rounded to rough figures that emphasize the first digit in the contractual number (Carslaw, 1988), which gives managers strong incentives to round up reported earnings and revenues to meet the contractual numbers.

This study extends the rounding phenomenon literature to the not well-explored OTC markets. The U.S. OTC market includes the OTC Bulletin Board (OTCBB) market and the OTC Pink Sheets (OTCPS) market. The OTCBB is an electronic quotation medium operated by the National Association of Securities Dealers (NASD) and the OTCPS is an American financial market providing price and liquidity information for almost 10,000 OTC securities. OTC-listed stocks are not subject to the mandatory SEC disclosure requirements under the 1934 Securities Exchange Act prior to 1999. Many firms in the OTC markets do not meet the listing requirements to trade on the major stock exchanges such as NYSE, NASDAQ, and AMEX. Their voluntarily disclosed financial statements are not audited.

A limited number of research studies focus on the OTC markets. Luft et al. (2001) is a pioneer study. This study finds that a portfolio of equally weighted OTCBB securities would have yielded a lower return and a higher risk than those formed on the major stock exchange markets. They also find that the relationship of returns of OTCBB to the securities listed on the major exchanges is relatively weak due to the lack of financial information and poor liquidity. Luft and Levine (2004) extend the previous study to examine how market capitalization and liquidity impact risk, return, and market microstructure for these securities. They document that the largest $20 \%$ of the OTC firms have higher returns and lower volatilities and suggest that if investors want to pursue an OTCBB investment strategy, they should focus on the largest $20 \%$ of the OTC firms. Bushee and Leuz (2005) examine the economic consequences of a regulatory change mandating OTCBB firms to comply with reporting requirements under the 1934 Securities Exchange Act. They find that the imposition of disclosure requirements results in significant costs for smaller firms and forces them off the OTCBB, while firms previously filing with SEC experience positive stock returns and permanent increases in liquidity. Duffie et al. (2005) examine how intermediation and asset prices in OTC markets are affected by illiquidity associated with search and bargaining and document that bid-ask spreads are lower if investors can more easily find other investors or have easier access to multiple market makers and with a monopolistic market maker, bid-ask spreads are higher if investors have easier access to the 
market maker. Bollen and Christie (2009) investigate the microstructure of the OTCPS market and document that market participants can develop effective norms with little guidance. Ang et al. (2013) explore the cross-sectional return premiums among different markets and find that compared with premiums in the major exchange markets, the OTC illiquidity premiums are several times higher; the size, value, and volatility premiums are similar; and the momentum premium is three times lower. Limits on short sales help explain these return premiums. Nofsinger and Varma (2014) find that OTC investors are older, relatively wealthier, and experienced in investing. Eraker and Ready (2015) find that returns on OTC stocks are extremely negative on average. Brüggemann et al. (2016) analyze a comprehensive sample of more than 10,000 U.S. OTC stocks and document that OTC firms that are subject to stricter regulatory regimes and disclosure requirements have a higher liquidity and lower crash risk. White (2016) analyzes 1.8 million trades by over 200,000 individual investors and finds that the typical OTC investment return is severely negative and investor outcomes worsen for OTC stocks that experience a promotional campaign or have weaker disclosure related eligibility requirements. He also finds that older, retired, low-income, and less-educated investors experience significantly poorer outcomes in OTC stock markets. Jiang et al. (2016) analyze OTCPS companies and document that firms classified into the Current Information category experienced an increase in liquidity while firms classified into the No Information category experienced a decrease in liquidity. Their study suggests that the increases in the salience of disclosure practices affect investors' attention, resulting in changes in trading behavior that ultimately translate into liquidity changes. In his dissertation paper, Davis (2016) compares trading characteristics of the top decile of performers versus those of the bottom decile of performers and finds that the winners are more illiquid, trade less during the sample period, and are less volatile than the losers. He also documents positive externalities resulting from the lottery-like features of penny stocks and finds that the larger and more liquid stocks and stocks in lower information tiers are easier to short. Ziegler and Neuenschwander (2017) analyze U.S. OTC stock transactions over the 250 trading days in 2015 and find that OTC stocks with high trading volumes and increasing float tend to experience the greatest level of short selling.

Since OTC companies disclose little financial information (Luft et al., 2001), Investors heavily rely upon reported revenues and earnings to make decisions. Firm managers may have strong incentives to round up reported earnings and revenues to raise investors' perception about a firm's future prospect as well as to meet the analysts' forecast. Therefore, we hypothesize:

\section{H1: OTC firms engage in rounding manipulations on reported earnings and revenues.}

OTCBB and OTCPS are the relatively unstructured and unregulated markets. Companies quoted on OTCBB and OTCPS lack of constraints on their behaviors and they are not required to submit audited financial reports. Aggarwal and Wu (2006) find that OTCBB and OTCPS-listed firms account for nearly half of the stock market manipulation cases pursued by the SEC from 1989 to 2001. White (2016) finds that when the OTC-listed companies have fewer disclosure-related eligibility requirements, they frequently become the targets of alleged market manipulations and generate more negative investment returns. This leads to the second hypothesis of this study:

H2: OTC firms are more aggressive in rounding up earnings and revenues than firms listed on the major U.S. stock exchanges.

On January 4, 1999, the SEC approved the eligibility rule, which required all OTCBB companies to comply with the disclosure requirements of the 1934 Security Exchange Act. About $76 \%$ of the firms not previously filing with the SEC chose not to comply with the required disclosures and were removed from the OTCBB (Bushee \& Leuz, 2005). Ang et al. (2013) postulate that improved financial disclosures could mitigate future stock bubbles. Without commitment to disclose financial information, firms may have more incentives to manipulate information in certain situations, such as when their performance is poor (Bushee $\&$ Leuz, 2005). Mandatory disclosure requirements of the eligibility rule may constrain managers' rounding manipulation behavior. Therefore, we hypothesize: 
H3: The enforcement of the eligibility rule in 1999 mitigates OTCBB firms' rounding manipulation activities.

\section{SAMPLES AND METHODOLOGY}

Our initial sample consists of all U.S. OTC companies in the COMPUSTAT database from 1960 to 2016. To be included in the final sample, firms need to have both annual revenue and net income information in CAMPUSTAT. The total number of sample observations with revenue data is 102,702 , comprised of 34,727 observations from the OTCBB market and 67,975 observations from the OTCPS market. The total number of qualified sample observations with positive earnings is 53,973, comprised of 20,850 observations from the OTCBB market and 33,123 observations form the OTCPS market. The total number of qualified sample observations with negative earnings is 57,515, comprised of 15,446 from the OTCBB market and 42,069 from the OTCPS market.

This study follows the methodologies developed by existing studies on rounding phenomenon. Benford's law suggests that the expected distributions of naturally occurring numbers are skewed toward the number zero in the second position of a multi-digit number. Benford (1938) documents that the expected proportions or occurrence of a number as the first digit in a number series can be approximated by the following equation:

proportion (a is the first digit) $=\log _{10}(a+1)-\log _{10}(a)$

The expected proportion of a given number $a$ as the first digit and the number $b$ as the second digit can be calculated with the following formula:

$\log _{10}\left(\mathrm{a}+\frac{b+1}{10}\right)-\log _{10}\left(\mathrm{a}+\frac{b}{10}\right)$

An overall expected proportion for $\mathrm{b}$ as the second digit can be found by summing over all possible $\mathrm{a}$ values for any $b$ value as follows:

proportion $(b$ is the second digit $)=\sum\left(\log _{10}\left(a+\frac{b+1}{10}\right)-\log _{10}\left(a+\frac{b}{10}\right)\right)$.

Table 1 provides the expected frequency (in percentage) for each digit in the second place of a number. If managers manipulate reported earnings and revenues by altering the actual financial numbers, then there would be significant deviations from the expected frequency in the second position.

TABLE 1

EXPECTED FREQUENCY OCCURRENCES FOR EACH DIGIT IN THE SECOND PLACES OF EARNINGS

$\begin{array}{lllllllllll}\text { Digit } & 0 & 1 & 2 & 3 & 4 & 5 & 6 & 7 & 8 & 9\end{array}$

Second Digit Expected

\begin{tabular}{lllllllllll} 
Frequency Percentage & 11.97 & 11.39 & 10.88 & 10.43 & 10.03 & 9.67 & 9.34 & 9.04 & 8.76 & 8.5 \\
\hline
\end{tabular}

Source: Nigrini and Mittermaier (1997).

To test the first hypothesis that OTC firms round up reported revenues and earnings, we compare the observed frequency for each number $\mathrm{x}$ in the second place of the reported revenues or earnings numbers to the expected occurrences of the number as predicted by Benford's law and reported in Table 1. This study 
uses a normally distributed Z-statistic to perform a significance test of the observed deviations from the expected proportions:

$\mathrm{Z}=\frac{\left|p-p_{0}\right|-\frac{1}{2 \mathrm{n}}}{\sqrt{\frac{p_{0}\left(1-p_{0}\right)}{n}}}$

where $\mathrm{p}$ and $\mathrm{p} 0$ are the observed and expected proportions, respectively. The sample size is represented by $\mathrm{n}$. The second term in the numerator is a correction term, and should be applied only when it is smaller than $|\mathrm{p}-\mathrm{p} 0|$ (Thomas, 1989). These Z-statistics would reject the null hypothesis at the ten, five, and one percent level if their values exceed $1.64,1.96$, and 2.57 , respectively.

Fleiss (1981, p23) is followed when calculating the Z-statistic of the difference in the deviation between two variables, such as the reported OTC firm revenues and the reported revenues from the major market listing firms. The formula used to calculate this difference is:

$Z=\frac{\left|p_{i}-p_{j}\right|-\frac{1}{2}\left(1 / n_{i}+1 / n_{j}\right)}{\sqrt{\overline{p q}\left(1 / n_{i}+1 / n_{j}\right)}}$

where $=1-,=n i /(n i+n j), n i$ is the total observations of variable $i, n j$ is the total number of observations of variable $\mathrm{j}$, $\mathrm{pi}=$ proportion of zero as the second digit of variable $\mathrm{i}$, and $\mathrm{pj}=$ proportion of zero as the second digit of variable $j$.

\section{EMPIRICAL RESULTS}

Table 2 presents the frequency distributions (in percentage) of each number ( 0 to 9 ) in the second place (digit) of reported net income and revenues of the sample OTC observations. In this and later tables, we report frequency distribution in the second digit of earnings for profit firms and loss firms separately in Panel A and Panel B, because as detailed earlier, profit firms and loss firms have different incentives in rounding the second digit of earnings. As shown in Panel A of Table 2, in regard to profit firms, 14.12 percent of the sample observations report zeros as the second digit of earnings. Compared to the expected frequency of 11.97 percent (as reported in Table 1), the deviation of 2.15 percent (14.12-11.97) is statistically significant at the $1 \%$ level $(\mathrm{z}=15.39)$. As shown in Panel B, 9.31 percent of all loss firm report nines in the second digit. Compared to the expected frequency of 8.50 percent (as reported in Table 1), the deviation of 0.81 percent $(9.31-8.50)$ is statistically significant at the $1 \%$ level $(\mathrm{z}=6.83)$. Panel $\mathrm{C}$ reports OTC firms' frequency distribution of the second digit of reported revenue . As shown in Panel C, 13.01 percent of the sample OTC firms report zeros in the second digit of reported revenues and the 1.04 (13.0111.97) percent frequency deviation is statistically significant at the one percent level $(\mathrm{z}=10.23)$. Taken together, results in Table 2 provide strong and consistent evidence in support of H1 that OTC firms round up earnings and revenues to achieve a higher reported earnings and revenues.

\section{TABLE 2 \\ FREQUENCY DISTRIBUTIONS OF SECOND DIGITS IN ANNUAL NET INCOME AND REVENUES FOR OTC FIRMS}

Panel A: Distributions of second digits in annual net income for profit firms

\begin{tabular}{ccccccccccc}
\hline & 0 & 1 & 2 & 3 & 4 & 5 & 6 & 7 & 8 & 9 \\
Net income & 14.12 & 11.56 & 10.81 & 10.34 & 9.61 & 9.62 & 9.04 & 8.74 & 8.59 & 7.58 \\
Deviation & 2.15 & 0.17 & -0.07 & -0.09 & -0.42 & -0.05 & -0.30 & -0.30 & -0.17 & -0.92 \\
Z statistics & 15.39 & 1.23 & 0.55 & 0.70 & 3.25 & 0.39 & 2.36 & 2.46 & 1.36 & 7.69 \\
\hline
\end{tabular}


Panel B: Distributions of second digits in annual net income for loss firms

\begin{tabular}{|c|c|c|c|c|c|c|c|c|c|c|}
\hline & 0 & 1 & 2 & 3 & 4 & 5 & 6 & 7 & 8 & 9 \\
\hline Net income & 12.16 & 11.29 & 10.48 & 10.18 & 9.96 & 9.45 & 9.14 & 8.96 & 9.07 & 9.31 \\
\hline Deviation & 0.19 & -0.10 & -0.40 & -0.25 & -0.07 & -0.22 & -0.20 & -0.08 & 0.31 & 0.81 \\
\hline Z statistics & 1.36 & 0.72 & 3.00 & 1.90 & 0.51 & 1.75 & 1.65 & 0.68 & 2.57 & 6.83 \\
\hline \multicolumn{11}{|c|}{ Panel C: Distributions of second digits in annual revenues } \\
\hline & 0 & 1 & 2 & 3 & 4 & 5 & 6 & 7 & 8 & 9 \\
\hline Revenue & 13.01 & 11.25 & 10.94 & 10.62 & 9.85 & 9.62 & 9.22 & 8.78 & 8.53 & 8.19 \\
\hline Deviation & 1.04 & -0.14 & 0.06 & 0.19 & -0.18 & -0.05 & -0.12 & -0.26 & -0.23 & -0.31 \\
\hline Z statistics & 10.23 & 1.39 & 0.59 & 1.94 & 1.94 & 0.54 & 1.34 & 2.92 & 2.56 & 3.54 \\
\hline
\end{tabular}

The OTC market consists of OTCBB and OTCPS. Next, we further examine firms in the OTCBB and OTCPS markets separately and present the results in Table 3. Panel A reports and compares the distribution of the second digit of earnings for profit firms in the OTCBB market and OTCPS market. As shown in Panel A, profit firms in both OTCBB market and OTCPS market both report higher frequencies of zeros in the second digit of earnings than expected (2.62 percent for OTCBB profit firms and 1.86 percent for OTCPS profit firms), and the deviations are both statistically significant at $1 \%$ level. When we compare the extent of rounding manipulations by profit firms listed in OTCBB market and OTCPS market, we observe that profit firms in OTCBB market is more aggressive in rounding up earnings than profit firms in the OTCPS market (difference in deviation is 0.76 percent, statistically significant at the $1 \%$ level). Panel B of Table 3 compares the distribution of the second digit of earnings for loss firms in the OTCBB market and OTCPS market. As shown in the panel, both the OTCBB loss firms and OTCPS loss firms report significantly higher frequencies of nines in the second digit in reported earnings. The deviation from expectation is 0.76 percent for OTCBB loss firms and 0.82 percent for OTCPS loss firms, both deviations are statistically significant at the $1 \%$ level. However, the difference in the deviation between OTCBB loss firms and OTCPS loss firms ( -0.06 percent) is not statically significant $(\mathrm{z}=0.20)$. Panel $\mathrm{C}$ of Table 3 compares the distribution of second digit in revenue for all firms in the OTCBB market and OTCPS market. As shown in the panel, firms in both the OTCBB market and the OTCPS market report significantly higher frequency of zeros in the second digit of revenue. The deviation is 0.61 percent for OTCBB firms and 1.25 percent for OTCPS firms, both are statistically significant at the $1 \%$ level. When we compare the difference in deviations between OTCBB firms and OTCPS firms, we find that OTCPS firms are more aggressive in rounding up revenues than OTCBB firms (the difference in deviation is -0.64 percent, statistically significant at $1 \%$ level). Taken together, results in Table 3 provide confirming evidence that firms in both the OTCBB market and OTCPS market round up their earnings and revenues, while OTCBB firms are more aggressive in rounding up earnings and less aggressive in rounding up revenues, as compared to OTCPS firms. 


\section{TABLE 3}

\section{FREQUENCY DISTRIBUTIONS OF SECOND DIGITS IN EARNINGS AND REVENUES FOR}

OTCBB FIRMS AND OTCPS FIRMS

\section{Panel A: Frequency distribution of the second digits of earnings for profit firms}

\begin{tabular}{ccccccccccc}
\hline OTCBB & 0 & 1 & 2 & 3 & 4 & 5 & 6 & 7 & 8 & 9 \\
earnings & 14.59 & 11.56 & 10.94 & 9.91 & 9.52 & 9.92 & 8.96 & 8.93 & 8.36 & 7.31 \\
Deviation & 2.62 & 0.17 & 0.06 & -0.52 & -0.51 & 0.25 & -0.38 & -0.11 & -0.40 & -1.19 \\
Z statistics & 11.64 & 0.76 & 0.27 & 2.43 & 2.44 & 1.23 & 1.88 & 0.56 & 2.03 & 6.15 \\
& & & & & & & & & & \\
OTCPS & & & & & & & & & & \\
earnings & 13.83 & 11.56 & 10.72 & 10.60 & 9.66 & 9.43 & 9.10 & 8.62 & 8.74 & 7.74 \\
Deviation & 1.86 & 0.17 & -0.16 & 0.17 & -0.37 & -0.24 & -0.24 & -0.42 & -0.02 & -0.76 \\
Z statistics & 10.40 & 0.96 & 0.92 & 1.02 & 2.21 & 1.48 & 1.51 & 2.68 & 0.12 & 4.92 \\
& & & & & & & & & & \\
OTCBB vs & & & & & & & & & & \\
OTCPS & & & & & & & & & & \\
Difference & 0.76 & 0.00 & 0.22 & -0.69 & -0.14 & 0.49 & -0.14 & 0.31 & -0.38 & -0.43 \\
Z statistics & 2.46 & -0.01 & 0.79 & 2.55 & 0.54 & 1.88 & 0.53 & 1.22 & 1.52 & 1.84 \\
\hline
\end{tabular}

Panel B: Frequency distribution of the second digits of earnings for loss firms

\begin{tabular}{ccccccccccc}
\hline OTCBB & 0 & 1 & 2 & 3 & 4 & 5 & 6 & 7 & 8 & 9 \\
earnings & 12.12 & 11.71 & 10.21 & 10.16 & 9.90 & 9.07 & 9.26 & 8.94 & 9.38 & 9.26 \\
Deviation & 0.15 & 0.32 & -0.67 & -0.27 & -0.13 & -0.60 & -0.08 & -0.10 & 0.62 & 0.76 \\
Z statistics & 0.55 & 1.20 & 2.62 & 1.08 & 0.53 & 2.48 & 0.32 & 0.41 & 2.68 & 3.33 \\
& & & & & & & & & & \\
OTCPS & & & & & & & & & & \\
earnings & 12.17 & 11.14 & 10.58 & 10.19 & 9.99 & 9.59 & 9.09 & 8.96 & 8.95 & 9.32 \\
Deviation & 0.20 & -0.25 & -0.30 & -0.24 & -0.04 & -0.08 & -0.25 & -0.08 & 0.19 & 0.82 \\
Z statistics & 1.25 & 1.57 & 1.92 & 1.55 & 0.26 & 0.54 & 1.73 & 0.53 & 1.38 & 5.96 \\
& & & & & & & & & & \\
OTCBB vs & & & & & & & & & & \\
OTCPS & & & & & & & & & & \\
Difference & -0.05 & 0.56 & -0.37 & -0.04 & -0.09 & -0.52 & 0.17 & -0.02 & 0.43 & -0.06 \\
Z statistics & 0.15 & 1.85 & 1.27 & 0.12 & 0.31 & 1.85 & 0.61 & 0.07 & 1.55 & 0.20 \\
\hline
\end{tabular}


Panel C: Frequency distribution of the second digits of revenues

\begin{tabular}{ccccccccccc}
\hline OTCBB & 0 & 1 & 2 & 3 & 4 & 5 & 6 & 7 & 8 & 9 \\
earnings & 12.58 & 11.50 & 11.05 & 10.58 & 9.81 & 9.68 & 9.31 & 8.81 & 8.46 & 8.21 \\
Deviation & 0.61 & 0.11 & 0.17 & 0.15 & -0.22 & 0.01 & -0.03 & -0.23 & -0.30 & -0.29 \\
Z statistics & 3.50 & 0.66 & 1.00 & 0.92 & 1.33 & 0.04 & 0.17 & 1.49 & 1.99 & 1.91 \\
& & & & & & & & & & \\
OTCPS & & & & & & & & & & \\
earnings & 13.22 & 11.12 & 10.88 & 10.63 & 9.87 & 9.59 & 9.17 & 8.76 & 8.57 & 8.18 \\
Deviation & 1.25 & -0.27 & 0.00 & 0.20 & -0.16 & -0.08 & -0.17 & -0.28 & -0.19 & -0.32 \\
Z statistics & 10.07 & 2.18 & 0.00 & 1.72 & 1.42 & 0.70 & 1.52 & 2.52 & 1.72 & 2.98 \\
& & & & & & & & & & \\
OTCBB vs & & & & & & & & & & \\
OTCPS & & & & & & & & & & \\
Difference & -0.64 & 0.38 & 0.17 & -0.05 & -0.05 & 0.09 & 0.14 & 0.05 & -0.11 & 0.03 \\
Z statistics & 2.89 & 1.82 & 0.81 & 0.23 & 0.25 & 0.44 & 0.74 & 0.24 & 0.61 & 0.16 \\
\hline
\end{tabular}

In the next analysis, we compare the extent of rounding manipulation by firms listed in the OTC market with that by firms listed in the major U.S. stock exchanges. To carry out the test, we first replicates previous studies to measure the extent of rounding manipulation on reported earnings and revenues by firms listed in major stock exchanges. We then compare the extent of rounding manipulation by firms in major stock exchanges and OTC market. We report our results in Table 4. Panel A of Table 4 reports results on earnings manipulation by profit firms, Panel B report results on earnings manipulation by loss firms, while Panel C reports results on revenue manipulation by all firms. As shown in the Panel A, the distribution of zeros in the second digit of earnings for profit firms in the major securities markets is 12.87 percent, and it deviates from the expectation by 0.90 percent; this deviation is statistically significant at the $1 \%$ level $(\mathrm{z}=11.36)$. This provides evidence that profit firms listed in major stock exchanges round up their earnings, as documented by prior studies. When we compare the deviation for profit firms listed in major stock exchanges with the deviation for profit firms listed in the OTC market, the deviation for profit firms in the OTC market (2.15 percent) is higher than the deviation for profit firms in the major stock exchanges $(0.90)$ and this difference in deviation of 1.25 percent $(2.15-0.90)$ is statistically significant at the $1 \%$ level $(\mathrm{z}$ =7.47). This provides evidence that profit firms in the OTC markets are more aggressive in rounding up earnings than profit firms in the major stock markets. Panel B of Table 4 reports the results for loss firms. As shown in the panel, the distribution of nines in the second digit of earnings for loss firms in major stock exchanges is 8.74 percent, and it deviates from the expectation by 0.24 percent; this deviation is marginally significant at $10 \%$ level $(\mathrm{z}=1.89)$. The deviation for loss firms in the OTC market is 0.81 percent, statistically significant at the $1 \%$ level $(\mathrm{z}=6.83)$. When we compare loss firms in the major stock exchanges and the OTC markets, the deviation for loss firms in the OTC market ( 0.81 percent) is higher than the deviation for loss firms in major stock exchanges $(0.24$ percent $)$, and this difference in deviation of 0.57 (0.81-0.24) is statistically significant at the $1 \%$ level $(\mathrm{z}=3.20)$, providing evidence that loss firms in OTC market are more aggressive in rounding down losses than loss firms in major stock markets. Lastly, Panel $\mathrm{C}$ reports results comparing the rounding manipulation of revenues for all firms in the major securities markets and all firms in the OTC markets. As shown in the panel, the distribution of zeros in the second digit of revenue is 12.25 percent for firms in major securities markets, and it deviates from the expectation by 0.28 percent. This deviation is statistically significant at $1 \%$ level $(\mathrm{z}=4.06)$. When we compare this deviation by firms in the major stock exchanges with the deviation by firms in OTC market, we can see the deviation for firms in OTC market (1.04) is higher than the deviation for firms in major stock exchanges $(0.28)$ and the difference in deviation of 0.76 percent $(1.04-0.28)$ is statistically significant at $1 \%$ level 
( $\mathrm{z}=5.99$ ). Overall, results in Table 4 provide consistent evidence in support of $\mathrm{H} 2$ that firms in the OTC market are more aggressive in rounding up earnings and revenues than firms in major stock exchanges.

TABLE 4

FREQUENCY DISTRIBUTIONS OF SECOND DIGITS IN EARNINGS AND REVENUES, OTC VS. MAJOR STOCK EXCHANGES

Panel A: Frequency distribution of the second digits of earnings for profit firms

\begin{tabular}{ccccccccccc}
\hline & 0 & 1 & 2 & 3 & 4 & 5 & 6 & 7 & 8 & 9 \\
Major markets & 12.87 & 11.49 & 10.89 & 10.41 & 9.94 & 9.66 & 9.29 & 8.93 & 8.60 & 7.90 \\
Deviation & 0.90 & 0.10 & 0.01 & -0.02 & -0.09 & -0.01 & -0.05 & -0.11 & -0.16 & -0.60 \\
Z statistics & 11.36 & 1.35 & 0.16 & 0.27 & 1.19 & 0.09 & 0.65 & 1.51 & 2.28 & 8.85 \\
& & & & & & & & & & \\
OTC markets & 14.12 & 11.56 & 10.81 & 10.34 & 9.61 & 9.62 & 9.04 & 8.74 & 8.59 & 7.58 \\
Deviation & 2.15 & 0.17 & -0.07 & -0.09 & -0.42 & -0.05 & -0.30 & -0.30 & -0.17 & -0.92 \\
Z statistics & 15.39 & 1.23 & 0.55 & 0.70 & 3.25 & 0.39 & 2.36 & 2.46 & 1.36 & 7.69 \\
& & & & & & & & & & \\
OTC vs Major & & & & & & & & & & \\
Markets & & & & & & & & & & \\
Difference & 1.25 & 0.06 & -0.09 & -0.07 & -0.33 & -0.04 & -0.25 & -0.20 & -0.01 & -0.32 \\
Z statistics & 7.47 & 0.40 & 0.56 & 0.47 & 2.25 & 0.29 & 1.74 & 1.40 & 0.06 & 2.41 \\
\hline
\end{tabular}

Panel B: Frequency distribution of the second digits of earnings for loss firms

\begin{tabular}{ccccccccccc}
\hline & 0 & 1 & 2 & 3 & 4 & 5 & 6 & 7 & 8 & 9 \\
Major markets & 11.61 & 11.38 & 10.77 & 10.65 & 10.19 & 9.78 & 9.17 & 9.05 & 8.67 & 8.74 \\
Deviation & -0.36 & -0.01 & -0.11 & 0.22 & 0.16 & 0.11 & -0.17 & 0.01 & -0.09 & 0.24 \\
Z statistics & 2.48 & 0.05 & 0.75 & 1.57 & 1.16 & 0.81 & 1.32 & 0.05 & 0.69 & 1.89 \\
& & & & & & & & & & \\
OTC markets & 12.16 & 11.29 & 10.48 & 10.18 & 9.96 & 9.45 & 9.14 & 8.96 & 9.07 & 9.31 \\
$\quad$ Deviation & 0.19 & -0.10 & -0.40 & -0.25 & -0.07 & -0.22 & -0.20 & -0.08 & 0.31 & 0.81 \\
Z statistics & 1.36 & 0.72 & 3.00 & 1.90 & 0.51 & 1.75 & 1.65 & 0.68 & 2.57 & 6.83 \\
& & & & & & & & & & \\
OTC vs Major & & & & & & & & & & \\
Markets & & & & & & & & & & \\
Difference & 0.55 & -0.09 & -0.29 & -0.46 & -0.22 & -0.33 & -0.03 & -0.09 & 0.40 & 0.57 \\
Z statistics & 2.75 & 0.45 & 1.51 & 2.44 & 1.19 & 1.80 & 0.16 & 0.50 & 2.25 & 3.20 \\
\hline
\end{tabular}


Panel C: Frequency distribution of the second digits of revenue

\begin{tabular}{ccccccccccc}
\hline & 0 & 1 & 2 & 3 & 4 & 5 & 6 & 7 & 8 & 9 \\
Major markets & 12.25 & 11.38 & 10.93 & 10.33 & 10.07 & 9.73 & 9.31 & 9.06 & 8.64 & 8.31 \\
Deviation & 0.28 & -0.01 & 0.05 & -0.10 & 0.04 & 0.06 & -0.03 & 0.02 & -0.12 & -0.19 \\
Z statistics & 4.06 & 0.19 & 0.69 & 1.58 & 0.59 & 0.87 & 0.53 & 0.40 & 1.93 & 3.16 \\
& & & & & & & & & & \\
OTC markets & 13.01 & 11.25 & 10.94 & 10.62 & 9.85 & 9.62 & 9.22 & 8.78 & 8.53 & 8.19 \\
Deviation & 1.04 & -0.14 & 0.06 & 0.19 & -0.18 & -0.05 & -0.12 & -0.26 & -0.23 & -0.31 \\
Z statistics & 10.23 & 1.39 & 0.59 & 1.94 & 1.94 & 0.54 & 1.34 & 2.92 & 2.56 & 3.54 \\
& & & & & & & & & & \\
OTC vs Major & & & & & & & & & & \\
Markets & & & & & & & & & & \\
Difference & 0.76 & -0.12 & 0.01 & 0.29 & -0.22 & -0.11 & -0.09 & -0.29 & -0.11 & -0.12 \\
Z statistics & 5.99 & 1.03 & 0.09 & 2.49 & 1.93 & 0.93 & 0.80 & 2.64 & 1.01 & 1.12 \\
\hline
\end{tabular}

All OTCBB firms are subject to the SEC reporting requirements after 1999; however, this rule does not affect OTCPS firms. In the next analysis, we examine the impact of this regulation on OTC firms' rounding manipulation behavior. We predict that the enforcement of the eligibility rule in 1999 mitigates OTCBB firms' rounding manipulation activities (H3). To carry out the test, we first examine the extent of rounding manipulation by OTCBB firms before and after the enforcement of SEC reporting requirement in 1999 and report the results in Table 5. Panel A and B reports the distribution of the second digit in earnings for OTCBB profit firms and loss firms respectively, while Panel $\mathrm{C}$ repots the distribution of the second digit in revenue for all OTCBB firms. As shown in Panel A, prior to 1999, the distribution of zeros in the second digit of earnings for OTCBB profit firms is 14.74 percent; it deviates from expectation by 2.77 percent and this deviation is statistically significant at the $1 \%$ level $(\mathrm{z}=11.97)$. After 1999 , the distribution of zeros in the second digit of earnings for profit firms is 12.08 percent; it deviates from the expectation by 0.11 percent, but this deviation is not statistically significant $(\mathrm{z}=0.06)$. Panel $\mathrm{B}$ reports results for loss firms. As shown in Panel B, prior to 1999, the distribution of nines in the second digit of earnings for OTCBB loss firms is 9.28 percent; it deviates from expectation by 0.78 percent and this deviation is statistically significant $(\mathrm{z}=3.17)$. After 1999, the distribution of nines in the second digit of earnings OTCBB loss firms is 9.03 percent. It deviates from the expectation by 0.53 percent, but this deviation is not statistically significant $(\mathrm{z}=0.53)$. Lastly, as reported in Panel $\mathrm{C}$, the distribution of zeros in the second digit of revenue for OTCBB firms is 12.61 percent prior to 1999 . It deviates from expectation by 0.64 percent and this deviation is statistically significant $(\mathrm{z}=3.49)$. However, after 1999, the distribution of zeros in the second digit of earnings is 12.53 percent. It deviates from the expectation by 0.56 percent, but this deviation is not statistically significant $(\mathrm{z}=0.84)$. Overall, results in Table 5 provide consistent and strong evidence that in the time period before 1999, OTCBB firms round up both earnings and revenues; however, in the time period after 1999, OTCBB firms' rounding manipulation of earnings and revenues are no longer statistically significant 


\section{TABLE 5}

\section{FREQUENCY DISTRIBUTIONS OF SECOND DIGITS IN EARNINGS AND REVENUES FOR FIRMS LISTED IN OTCBB BEFORE AND AFTER 1999}

\section{Panel A: Frequency distribution of the second digits of earnings for profit firms}

\begin{tabular}{|c|c|c|c|c|c|c|c|c|c|c|}
\hline & 0 & 1 & 2 & 3 & 4 & 5 & 6 & 7 & 8 & 9 \\
\hline $\begin{array}{c}\text { Prior to } 1999 \\
\text { earnings }\end{array}$ & 14.74 & 11.57 & 10.97 & 9.84 & 9.49 & 9.97 & 8.97 & 8.93 & 8.30 & 7.22 \\
\hline Deviation & 2.77 & 0.18 & 0.09 & -0.59 & -0.54 & 0.30 & -0.37 & -0.11 & -0.46 & -1.28 \\
\hline Z statistics & 11.97 & 0.79 & 0.39 & 2.71 & 2.52 & 1.44 & 1.77 & 0.55 & 2.26 & 6.42 \\
\hline $\begin{array}{l}\text { After } 1999 \\
\text { earnings }\end{array}$ & 12.08 & 11.13 & 10.94 & 11.23 & 10.28 & 8.77 & 8.58 & 8.77 & 9.25 & 8.96 \\
\hline Deviation & 0.11 & -0.26 & 0.06 & 0.80 & 0.25 & -0.90 & -0.76 & -0.27 & 0.49 & 0.46 \\
\hline Z statistics & 0.06 & 0.22 & 0.02 & 0.80 & 0.22 & 0.94 & 0.79 & 0.25 & 0.50 & 0.48 \\
\hline \multicolumn{11}{|c|}{$\begin{array}{l}\text { Prior to } 1999 \text { vs } \\
\text { After } 1999\end{array}$} \\
\hline Difference & 2.66 & 0.44 & 0.02 & -1.39 & -0.79 & 1.20 & 0.39 & 0.15 & -0.94 & -1.74 \\
\hline $\mathrm{Z}$ statistics & 2.35 & 0.39 & -0.03 & 1.42 & 0.81 & 1.22 & 0.37 & 0.11 & 1.02 & 2.06 \\
\hline \multicolumn{11}{|c|}{ Panel B: Frequency distribution of the second digits of earnings for loss firms } \\
\hline & 0 & 1 & 2 & 3 & 4 & 5 & 6 & 7 & 8 & 9 \\
\hline $\begin{array}{c}\text { Prior to } 1999 \\
\text { earnings }\end{array}$ & 12.07 & 11.58 & 10.29 & 10.34 & 9.99 & 9.16 & 9.15 & 8.83 & 9.32 & 9.28 \\
\hline Deviation & 0.10 & 0.19 & -0.59 & -0.09 & -0.04 & -0.51 & -0.19 & -0.21 & 0.56 & 0.78 \\
\hline Z statistics & 0.34 & 0.67 & 2.16 & 0.32 & 0.14 & 1.95 & 0.74 & 0.84 & 2.23 & 3.17 \\
\hline $\begin{array}{l}\text { After } 1999 \\
\text { earnings }\end{array}$ & 12.42 & 12.64 & 9.52 & 8.81 & 9.52 & 8.37 & 10.18 & 9.63 & 9.85 & 9.03 \\
\hline Deviation & 0.45 & 1.25 & -1.36 & -1.62 & -0.51 & -1.30 & 0.84 & 0.59 & 1.09 & 0.53 \\
\hline Z statistics & 0.56 & 1.65 & 1.82 & 2.22 & 0.68 & 1.83 & 1.19 & 0.84 & 1.61 & 0.77 \\
\hline \multicolumn{11}{|l|}{$\begin{array}{l}\text { Prior to } 1999 \text { vs } \\
\quad \text { After } 1999\end{array}$} \\
\hline Difference & -0.35 & -1.06 & 0.76 & 1.53 & 0.47 & 0.79 & -1.03 & -0.81 & -0.54 & 0.25 \\
\hline $\mathrm{Z}$ statistics & 0.40 & 1.29 & 0.97 & 1.99 & 0.58 & 1.06 & 1.38 & 1.09 & 0.69 & 0.30 \\
\hline
\end{tabular}


Panel C: Frequency distribution of the second digits of revenues

\begin{tabular}{ccccccccccc}
\hline & 0 & 1 & 2 & 3 & 4 & 5 & 6 & 7 & 8 & 9 \\
Prior to 1999 & & & & & & & & & & \\
earnings & 12.61 & 11.52 & 10.95 & 10.57 & 9.80 & 9.73 & 9.34 & 8.87 & 8.46 & 8.16 \\
Deviation & 0.64 & 0.13 & 0.07 & 0.14 & -0.23 & 0.06 & 0.00 & -0.17 & -0.30 & -0.34 \\
Z statistics & 3.49 & 0.74 & 0.36 & 0.80 & 1.38 & 0.38 & 0.01 & 1.07 & 1.88 & 2.18 \\
& & & & & & & & & & \\
After 1999 & & & & & & & & & & \\
earnings & 12.53 & 11.47 & 11.98 & 10.81 & 10.22 & 8.77 & 8.77 & 8.14 & 8.42 & 8.89 \\
Deviation & 0.56 & 0.08 & 1.10 & 0.38 & 0.19 & -0.90 & -0.57 & -0.90 & -0.34 & 0.39 \\
Z statistics & 0.84 & 0.10 & 1.76 & 0.59 & 0.29 & 1.50 & 0.95 & 1.54 & 0.58 & 0.67 \\
& & & & & & & & & & \\
Prior to 1999 vs & & & & & & & & & & \\
After 1999 & & & & & & & & & & \\
Difference & 0.08 & 0.06 & -1.03 & -0.23 & -0.43 & 0.95 & 0.58 & 0.73 & 0.04 & -0.74 \\
Z statistics & 0.08 & 0.06 & 1.57 & 0.33 & 0.66 & 1.52 & 0.93 & 1.21 & 0.03 & 1.27 \\
\hline
\end{tabular}

There are two alternative explanations for the lack of rounding manipulation by OTCBB firms in the period after 1999. One explanation is that the enforcement of the eligibility rule in 1999 mitigated OTCBB firms' rounding manipulation activities, as predicted in $\mathrm{H} 3$. The alternative explanation is that the lack of rounding manipulation by OTCBB firms after 1999 is due to time period effect. To explore this possibility, we examine whether, like the OTCBB firms, OTCPS firms also show a lack of rounding manipulation after 1999. The logic is as follows. The enforcement of the eligibility rule in 1999 applies only to OTCBB firms, but not OTCPS firms; therefore, if we observe that OTCPS firms are still active in rounding manipulations after 1999, then the lack of rounding manipulation by OTCBB firms after 1999 is likely due to the enforcement of the eligibility rule. On the other hand, if we observe a lack of rounding manipulation for OTCPS firms in the period after 1999 as well, then the decrease in rounding manipulations could be due to be due to time period effects. To carry out the test, we examine the distribution of the second digit in earnings and revenue for OTCPS firms after 1999 and report the results in Table 6. As shown in Panel A, the distribution of zeros in the second digit of net income for OTCPC profit firms is 12.93 percent and it deviates from expectation by 0.96 percent; this deviation is statistically significant $(z=3.45)$. Results in Panel B show that after 1999, the distribution of nines in the second digit of earnings of loss firms listed in OTCPS market is 9.30 . It deviates from the expectation by 0.80 percent and this deviation is statistically significant at 1\% level $(\mathrm{z}=4.48)$. Results in Panel $\mathrm{C}$ show that after 1999 the distribution of zeros in the second digit of revenue for OTCPS firms is 13.62. It deviates from the expectation by 1.65 percent and this deviation is statistically significant at the $1 \%$ level $(\mathrm{z}=8.94)$. Taken together, results in Table 6 provide strong evidence that in the time period after 1999, OTCPS firms still round up their earnings and revenues. This suggests that the lack of rounding manipulation by OTCBB firms after 1999 is likely due to the enforcement of the eligibility rules, rather than a time period effect. Combining results in Table 5 and Table 6 , we conclude that as predicted in $\mathrm{H} 3$, the eligibility rule mitigates the rounding manipulation activities by OTCBB firms. 


\section{TABLE 6 \\ FREQUENCY DISTRIBUTIONS OF SECOND DIGITS IN EARNINGS AND REVENUES FOR FIRMS LISTED IN OTCPS AFTER 1999}

Panel A: Frequency distribution of the second digits of earnings for profit firms

\begin{tabular}{ccccccccccc}
\hline & 0 & 1 & 2 & 3 & 4 & 5 & 6 & 7 & 8 & 9 \\
After 1999 & & & & & & & & & & \\
OTCPS earnings & 12.93 & 11.89 & 10.31 & 10.62 & 9.62 & 9.51 & 9.07 & 8.68 & 9.07 & 8.29 \\
Deviation & 0.96 & 0.50 & -0.57 & 0.19 & -0.41 & -0.16 & -0.27 & -0.36 & 0.31 & -0.21 \\
Z statistics & 3.45 & 1.81 & 2.12 & 0.70 & 1.58 & 0.61 & 1.06 & 1.44 & 1.27 & 0.84 \\
\hline
\end{tabular}

Panel B: Frequency distribution of the second digits of earnings for loss firms

\begin{tabular}{|c|c|c|c|c|c|c|c|c|c|c|}
\hline After 1999 & 0 & 1 & 2 & 3 & 4 & 5 & 6 & 7 & 8 & 9 \\
\hline OTCPS earnings & 12.25 & 11.40 & 10.39 & 10.18 & 9.79 & 9.67 & 9.15 & 9.06 & 8.79 & 9.30 \\
\hline Difference & 0.28 & 0.01 & -0.49 & -0.25 & -0.24 & 0.02 & -0.19 & 0.02 & 0.03 & 0.80 \\
\hline Z statistics & 1.37 & 0.03 & 2.45 & 1.27 & 1.24 & 0.09 & 1.00 & 0.07 & 0.16 & 4.48 \\
\hline \multicolumn{11}{|c|}{ Panel C: Frequency distribution of the second digits of revenues } \\
\hline After 1999 & 0 & 1 & 2 & 3 & 4 & 5 & 6 & 7 & 8 & 9 \\
\hline OTCPS earnings & 13.62 & 11.12 & 10.89 & 10.37 & 9.80 & 9.61 & 9.14 & 8.69 & 8.37 & 8.40 \\
\hline Difference & 1.65 & -0.27 & 0.01 & -0.06 & -0.23 & -0.06 & -0.20 & -0.35 & -0.39 & -0.10 \\
\hline Z statistics & 8.94 & 1.50 & 0.05 & 0.33 & 1.35 & 0.34 & 1.21 & 2.13 & 2.44 & 0.65 \\
\hline
\end{tabular}

\section{CONCLUSIONS}

In this study, we examine the rounding manipulation behavior by firms listed in the OTC market. We find that (1) OTC quoted firms engage in rounding manipulations on reported earnings and revenues; (2) rounding manipulation by OTC firms is more severe than that by firms listed in major U.S. stock exchanges; and (3) the enhanced disclosure requirements in 1999 reduced OTCBB firms' rounding manipulation activities.

This paper contributes to the current literature as follows. First, it extends the rounding phenomenon literature to the OTC market - it provides the first piece of empirical evidence that firms in the OTC market engage in rounding manipulations of earnings and revenue. Results from this study also help scholars and investors better understand the less-explored OTC market. This study also have important policy implications. In particular, it documents the impact of the enforcement of the eligibility rule on firms' rounding manipulation activities. It provides feedback to policy makers and regulators on the effectiveness of the mandatory SEC disclosure requirement on OTC firms' financial reporting quality.

\section{REFERENCES}

Ang, A., Shtauber, A.A., \& Tetlock, P.C. (2013). Asset pricing in the dark: The cross-section of OTC stocks. The Review of Financial Studies, 26(12), 2985-3028.

Benford, F. (1938). The law of anomalous numbers. Proceedings of the American Philosophical Society, pp. 551-572.

Bollen, N.P., \& Christie, W.G. (2009). Market microstructure of the Pink Sheets. Journal of Banking \& Finance, 33(7), 1326-1339. 
Brenner, G.A., \& Brenner, R. (1982). Memory and markets, or why are you paying $\$ 2.99$ for a widget? Journal of Business, pp. 147-158.

Brüggemann, U., Kaul, A., Leuz, C., \& Werner, I.M. (2016). The Twilight Zone: OTC Regulatory Regimes and Market Quality. Initiative on Global Markets. The University of Chicago.

Bushee, B.J., \& Leuz, C. (2005). Economic consequences of SEC disclosure regulation: Evidence from the OTC bulletin board. Journal of Accounting and Economics, 39(2), 233-264.

Carslaw, C.A. (1988). Anomalies in income numbers: Evidence of goal oriented behavior. Accounting Review, pp. 321-327.

Das, S., \& Zhang, H. (2003). Rounding-up in reported EPS, behavioral thresholds, and earnings management. Journal of Accounting and Economics, 35(1), 31-50.

Davis, R. (2016). Prices, Trading Activity, And Market Quality in The Modern OTC Marketplace. Dissertation.

Duffie, D., Gârleanu, N., \& Pedersen, L.H. (2005). Over-the-counter markets. Econometrica, 73(6), 1815-1847.

Eraker, B., \& Ready, M. (2015). Do investors overpay for stocks with lottery-like payoffs? An examination of the returns of OTC stocks. Journal of Financial Economics, 115(3), 486-504.

Fleiss, J.L., Levin, B., \& Paik, M.C. (2013). Statistical methods for rates and proportions. John Wiley \& Sons.

Guan, L., He, S.D., \& McEldowney, J. (2008). Window dressing in reported earnings. Com. Lending Rev., 23, 26.

He, D., Koo, M., \& Guan, L. (2012). The rounding of revenues and earnings by publicly-listed companies in the United States, 1950-2010: An Empirical Analysis. International Journal of Management, forthcoming.

Jiang, J., Petroni, K.R., \& Wang, I.Y. (2016). Private intermediary innovation and market liquidity: Evidence from the Pink Sheets ${ }^{\circledR}$ market. Contemporary Accounting Research, 33(3), 920-948.

Kinnunen, J., \& Koskela, M. (2003). Who is miss world in cosmetic earnings management? A crossnational comparison of small upward rounding of net income numbers among eighteen countries. Journal of International Accounting Research, 2, 39-69.

Luft, C., \& Levine, L.M. (2004). Over the counter bulletin board exchange: The impact of liquidity and size to return, volatility, and bid/ask spread. The Journal of Alternative Investments, 7(3), 95-106.

Luft, C., Levine, L.M., \& Larson, S. (2001). Over the Counter Bulletin Board Exchange: Market structure, risk, and return. The Journal of Alternative Investments, 4(2), 33-42.

Nofsinger, J.R., \& Varma, A. (2014). Pound wise and penny foolish? OTC stock investor behavior. Review of Behavioral Finance, 6(1).

Securities and Exchange Commission. (2006). Final report of the advisory committee on smaller public companies to the United Stated Securities and Exchange Commission. Retrieved from http;//www.sec.gov/info/smallbus/acspc/acspc-finalreport.pdf

Skousen, C.J., Guan, L., \& Wetzel, T.S. (2004). Anomalies and unusual patterns in reported earnings: Japanese managers round earnings. Journal of International Financial Management \& Accounting, 15(3), 212-234.

Thomas, J.K. (1989). Unusual patterns in reported earnings. Accounting Review, pp. 773-787.

White, J.T. (2016, December 16). Outcomes of investing in OTC stocks. U.S. Securities and Exchange Commission, Division of Economic and Risk Analysis (DERA).

Ziegler, P., \& Neuenschwander, C. (2017). Over the Counter Delivery Failures: Characteristics which Predict Naked Short Selling. Journal of Finance and Accountancy, 21, 1-12. 